\section{Non-invasive ventilation in acute respiratory failure in children}

\author{
Clara Abadesso, Pedro Nunes, \\ Catarina Silvestre, Ester Matias, \\ Helena Loureiro, Helena Almeida \\ Pediatric Intensive Care Unit, Hospital \\ Fernando Fonseca, Amadora, Portugal
}

\section{Abstract}

The aim of this paper is to assess the clinical efficacy of non-invasive ventilation (NIV) in avoiding endotracheal intubation (ETI), to demonstrate clinical and gasometric improvement and to identify predictive risk factors associated with NIV failure. An observational prospective clinical study was carried out. Included Patients with acute respiratory disease (ARD) treated with NIV, from November 2006 to January 2010 in a Pediatric Intensive Care Unit (PICU). NIV was used in 151 patients with acute respiratory failure (ARF). Patients were divided in two groups: NIV success and NIV failure, if ETI was required. Mean age was $7.2 \pm 20.3$ months (median: 1 min: 0,3 max.: 156). Main diagnoses were bronchiolitis in 102 (67.5\%), and pneumonia in 44 (29\%) patients. There was a significant improvement in respiratory rate (RR), heart rate ( $\mathrm{HR}), \mathrm{pH}$, and $\mathrm{pCO}_{2}$ at $2,6,12$ and 24 hours after NIV onset $(\mathrm{P}<0.05)$ in both groups. Improvement in pulse oximetric saturation/fraction of inspired oxygen $\left(\mathrm{SpO}_{2} / \mathrm{FiO}_{2}\right)$ was verified at 2, 4, 6, 12 and 24 hours after NIV onset in the success group $(\mathrm{P}<0.001)$. In the failure group, significant $\mathrm{SpO}_{2} / \mathrm{FiO}_{2}$ improvement was only observed in the first 4 hours. NIV failure occurred in 34 patients (22.5\%). Risk factors for NIV failure were apnea, prematurity, pneumonia, and bacterial co-infection $(\mathrm{P}<0.05)$. Independent risk factors for NIV failure were apneia $(\mathrm{P}<0.001$; odds ratio $15.8 ; 95 \%$ confidence interval: $3.42-71.4)$ and pneumonia ( $\mathrm{P}<0.001$, odds ratio $31.25 ; 95 \%$ confidence interval: 8.33-111.11). There were no major complications related with NIV. In conclusion this study demonstrates the efficacy of NIV as a form of respiratory support for children and infants with ARF, preventing clinical deterioration and avoiding ETI in most of the patients. Risk factors for failure were related with immaturity and severe infection.

\section{Introduction}

Non-invasive ventilation (NIV) is a relatively new ventilatory mode that has been increas- ingly used in the acute setting over the past 15 years, demonstrating beneficial effects in the adult and pediatric population with different types of respiratory failure. . $^{-4}$ NIV recruits the lung, increasing functional residual capacity, improves respiratory dynamics, reduces respiratory work, and optimizes gas exchange. 4

Several studies in the adult populations have shown that NIV is a safe and effective therapy for patients with hypercapnic acute respiratory failure (ARF) due to chronic obstructive pulmonary disease (COPD) exacerbation, hypoxemic ARF due to cardiogenic pulmonary edema or community-acquired pneumonia, and ARF in the immunocompromised patients with pulmonary infiltrates. ${ }^{2,5}$ In these patients, NIV is associated with an improvement in respiratory status and a reduction in the length of stay in the intensive care unit, and in mortality.2,5 It diminishes the rate of intubation when compared to conventional medical therapy, and the risk of ventilator associated pneumonia and other nosocomial infections. ${ }^{5,6}$ The overall effectiveness of NIV in avoiding intubation ranges from $69-79 \%$ in randomized studies. ${ }^{6}$ In adults with mixed types of respiratory failure, including severe hypoxemia, the evidence in support of NIV is less strong. ${ }^{6,7}$ In hypoxemic ARF due to acute respiratory distress syndrome (ARDS) /acute lung injury (ALI), NIV should be applied in carefully selected patients. When patients have a high severity score, older age, ARDS, pneumonia, or fail to improve pulse oximetric saturation/fraction of inspired oxygen $\left(\mathrm{SpO}_{2} / \mathrm{FiO}_{2}\right)$ after $1 \mathrm{~h}$ of treatment, the risk of failure is higher. ${ }^{5-7}$ The best-documented application of NIV in pediatric patients is in chronic patients in the home setting. NIV has proven to improve or reverse nocturnal hypoventilation in infants and children with various causes of chronic respiratory failure, such as neuromuscular diseases, severe upper airway obstruction and cystic fibrosis.1,3,4 NIV is also a well-established therapy in neonates for early stabilization in very low birth weight newborns, as a primary mode for respiratory distress syndrome treatment, in the management of apnea of prematurity and for prevention of extubation failures. ${ }^{7}$ During the last 10 years NIV has been increasingly used in children with acute respiratory distress. Although the reported studies on this form of ventilatory support are mainly retrospective, non-controlled clinical trials and little case series are being increasingly published and recently prospective studies have shown that NIV appears to be a safe and effective treatment in children with acute respiratory problems. ${ }^{8-22}$ The success of treatment with NIV was documented by clinical and laboratory parameters such as respiratory rate (RR) and cardiac rate (HR) and improvement of blood gas variables. ${ }^{8-15}$

$\mathrm{NIV}$ is being considered by many centers as
Correspondence: Clara Abadesso, Pediatric Intensive Care Unit, Hospital Fernando Fonseca, IC 19, 2720-276, Amadora, Portugal.

Tel: +351917905002 .

E-mail: clara_abadesso@hotmail.com

Key words: non-invasive ventilation, acute respiratory failure, child, infant, predictive factors, pediatric intensive care unit.

Acknowledgments: we thank Dr. Michele Costa for helping in the translation of this manuscript. We thank our nursing staff for their involvement in learning and performing non-invasive ventilation, with great cooperation and enthusiasm.

Contributions: CA, PN, conception and design, acquisition of data, analysis and interpretation of data, drafting the article and revising it critically; CS, HA, conception and design, acquisition of data, analysis and interpretation of data, revising the article critically; EM, HL, acquisition of data, analysis and interpretation of data; revising the article critically.

Conflict of interests: all authors declare that there are no conflicts of interest.

Received for publication: 5 February 2012.

Revision received:

Accepted for publication:

This work is licensed under a Creative Commons Attribution NonCommercial 3.0 License (CC BYNC 3.0).

(C) Copyright C. Abadesso et al., 2012

Licensee PAGEPress, Italy

Pediatric Reports 2012; 4:e16

doi:10.4081/pr.2012.e16

an early alternative form of ventilatory support for acute respiratory failure.9,15 Information on pediatric NIV characteristics and risk factors for NIV failure in children are useful to improve therapeutic strategies of respiratory support. We report our experience with the use of NIV as a primary ventilatory support in children admitted to our Pediatric Intensive care Unit (PICU), with acute respiratory distress.

The primary objective of the present study was to assess the clinical efficacy of NIV in avoiding endotracheal intubation and to demonstrate clinical and gasometrical improvement in those patients. The secondary objective was to identify predictive risk factors associated with NIV failure and the need for endotracheal intubation.

\section{Materials and Methods}

The study was performed in a PICU with 5 intensive care beds and 6 special care beds. 


\section{Intervention}

NIV was used as a primary ventilatory support in patients with acute respiratory distress/failure, with the objective of clinical improvement and avoidance of endotracheal intubation. We used a written standardized protocol, based on the guidelines published by Respiratory Group of the Spanish Society of Pediatric Intensive Care. ${ }^{23}$

\section{Design and setting}

This is a cohort study with prospective data collection regarding patients treated with NIV. We considered two groups: a success group, where clinical and gasometric improvement was achieved and a failure group, where intubation was necessary.

\section{Study period}

From November 2006 to January 2010 (3 years and 2 months).

\section{Patients}

We included patients admitted to our PICU with need of NIV as a primary ventilation mode. The inclusion criteria were: acute respiratory failure (hypoxemia - transcutaneous oxygen saturation $\left(\mathrm{SpO}_{2}\right)<92 \%$ at room air and capillary or venous $\mathrm{pCO}_{2}>50-60 \mathrm{mmHg}$ ), exacerbation of chronic respiratory failure, severe upper airway obstruction and apnea. Clinical status of the patient and the work of breathing were also important factors when deciding to begin NIV. Patients were selected regardless of the underlying disease process contributing to respiratory failure. Exclusion criteria were: cardiorespiratory arrest, hemodynamic instability despite vasoactive treatment, Glasgow coma score $<8$, need for airway protection or need of immediate intubation to avoid respiratory arrest. Patients with NIV after extubation were not included in this study, although we use it as a method of weaning from mechanical ventilation.

Bronchiolitis was defined as a respiratory disorder in children from 1 month to 2 years of age, presenting with rhinitis, tachypnea, cough, wheezing, crackles, and use of accessory muscles, with or without fever, and without a consolidation on the x-ray.

Viral pneumonia was defined as a respiratory disorder with a new or progressive infiltrate or consolidation on a chest x-ray, and tachypnea, cough, wheezing, crackles, and use of accessory muscles, with or without fever.

Bacterial co-infection was considered in the presence of at least two of the following: fever $>38^{\circ} \mathrm{C}$, increased C-reactive protein $>5 \mathrm{mg} / \mathrm{dL}$, leucocitosis $>15.000 \mathrm{~mm}^{3}$, and new or progressive infiltrate (interstitial, bronchial, alveolar) or consolidation on the chest X-ray.

These criteria were usually used to start antibiotics.

\section{Ventilatory support strategies}

The ventilatory strategy was based on the guidelines mentioned above. ${ }^{23}$

NIV was delivered by continuous (CPAP) or bi-level (BiPAP) positive airway pressure.

The interface to the patient was chosen between the following four (according to patient age, comfort and availability): nasal or mouth-nose mask, binasal short prosthesis and nasopharyngeal prosthesis (endotracheal tube with its extremity cut and placed on the nasopharynx).

Conventional (Drager Babylog 8000 plus ${ }^{\circledR}$ ) and specific NIV ventilators: Respironics BiPAP Vision ${ }^{\circledR}$, Respironics BiPAP Harmony ${ }^{\circledR}$, Infant Flow Driver ${ }^{\circledR}$, Infant Flow Advance ${ }^{\circledR /}$ SiPAP ${ }^{\circledR}$, were used to apply NIV.

CPAP was begun with 4-5 $\mathrm{cmH}_{2} \mathrm{O}$, and progressively increased the pressure according to the need/tolerance of the patient. $\mathrm{BiPaP}$ was begun with an expiratory positive airway pressure (EPAP) of 4-5 $\mathrm{cmH}_{2} \mathrm{O}$ and an inspiratory positive airway pressure (IPAP) of 8-10 cmH20. IPAP was then increased by $2 \mathrm{cmH}_{2} \mathrm{O}$ intervals according to the patient's needs and tolerance. CPAP or BIPAP was chosen depending on: if it was type I or type II acute respiratory failure, ventilators available or patient's tolerance/improvement.

The necessary inspiratory fraction of oxygen was used to maintain a $\mathrm{SpO}_{2}$ above $94 \%$. With the BiPaP Harmony ${ }^{\circledR}$, supplemental oxygen was administered through the circuit to achieve $\mathrm{SpO}_{2}>94 \%$. Ventilator parameters were adjusted according to clinic and gasometrical evolution. In every case a minimum respiratory backup frequency was programmed, ranging from 10 to $30 \mathrm{cpm}$ depending on the child's age. NIV was reduced progressively in accordance to the degree of clinical improvement, and was discontinued when the patient had normal RR for age, oxygen requirement $<40 \%$, a lower $\mathrm{pCO}_{2}$ without ventilatory support, and periods with good clinical tolerance without NIV support. This was a subjective decision, non-based on any specific standardized criteria.

\section{Standard treatment}

Nutritional support was delivered by continuous enteral feeding via naso or orogastric tube; this was also used to avoid gastric distension. The majority of the patients received chest physiotherapy in order to clear secretions using forced expiratory technique. Corticosteroids were never used for the treatment of bronchiolitis. Prevention of skin injury was made by the application of hidrocolloide/ colloid dressings (Askina ${ }^{\circledR}$ and Varihesive ${ }^{\circledR}$ gel control) on different facial pressure points.

Salbutamol nebulizer was used in patients who respond to it. Sedation was maintained with chloral hydrate $(30-50 \mathrm{mg} / \mathrm{kg})$ and myda- zolam boluses $(0.1 \mathrm{mg} / \mathrm{kg})$, in order to avoid patient-ventilator asynchrony, or in cases of severe agitation.

\section{Non-invasive ventilation outcome and end-points}

Patients were divided in two groups: NIV success (Group A) and NIV failure (Group B).

NIV success was defined as: i) objective reduction in respiratory effort, demonstrated by reduction in $\mathrm{RR}$ and $\mathrm{HR}$; ii) reduction in oxygen demand; iii) improvement in gasometric parameters ( $\mathrm{ph}, \mathrm{pCO}_{2}$ ). NIV failure was defined as the need for endotracheal intubation.

Intubation criteria were: absence of improvement, worsening of gasometric parameters or deterioration in the clinical status of the patient.

We analyzed risk factors associated with NIV failure.

\section{Data collection}

Clinical data collected: $\mathrm{RR}, \mathrm{HR}, \mathrm{SpO}_{2}$; capillary $\mathrm{pH}$ and $\mathrm{pCO}_{2}$ obtained before and at $2,4,6$, 12,24 and 48 h of NIV.

To estimate oxygenation we calculated pulse oximetric saturation/fraction of inspired oxygen $\left(\mathrm{SpO}_{2} / \mathrm{FiO}_{2}\right)$ as a non-invasive alternative to $\mathrm{PaO}_{2} / \mathrm{FiO}_{2}$. 24

Some patients do not have all of the gasometric evaluations in the referred time.

The following variables were also collected for each patient: age, sex, weight, personal relevant medical history (prematurity, chronic pulmonary disease, congenital cardiac disease), ARF type, ARF cause, NIV characteristics (type of mask, ventilator, NIV mode and used parameters), use of sedatives, NIV duration, NIV outcome, NIV complications, length of hospital stay and Pediatric Index of Mortality score (PIM).

\section{Statistical analyses}

Descriptive analysis: Results of quantitative variables were expressed in terms of mean, standard deviation, and median. Quantitative related continuous variables were compared using paired two-tailed t-test/Student T-test. Categorical values were expressed as a percentage, and compared using the $\chi^{2}$ test or the Fisher exact test when relevant.

Univariate and multivariate analyses of risk factors for NIV failure were performed using logistic regression. Independent predictive factors for NIV failure were determined by multivariate analyses.

A P value of $<0.05$ was considered statistically significant. 


\section{Results}

\section{Patients}

During the study period 1948 children were admitted in our Unit, 848 with respiratory disease. There were 149 children subjected to NIV in a total of 151 NIV episodes, with each episode treated as an independent event.

The mean age was $7.25 \pm 20.3$ months (median: 1 month; range 0.3-156 months). One hundred and twenty eight patients (84.7\%) were infants less than 6 month of age and 79 were $\leq 1$ month. Mean weight was $5.1 \pm 4.9 \mathrm{~kg}$ and 77 (51\%) were male.

Most of the episodes occurred between November and February of the studied years.

The most common primary diagnosis was bronchiolitis affecting 102 patients (67.5\%), followed by pneumonia in $44(29 \%)$. Other diagnosis were: atelectasis in 27 (18\%); apnea in $20(13.2 \%)$; bacterial co-infection in 43 (28.5\%); upper airway obstruction in 5 (nasopharyngeal carcinoma, multiple malformation syndrome, cervical hemalynphangioma, laryngomalacia); septic shock in 3; ARDS in 3 and pericardial effusion in 1.

Patients with bronchiolitis were significantly younger than those with pneumonia (1.6 \pm 2.24 months vs. $20.2 \pm 34.3 ; \mathrm{P}=0.00$ ).

Past relevant medical history: prematurity in $27(18 \%)$; chronic pulmonary disease in 10 (6.6\%); neurodevelopmental delay in 12 ; trisomy 21 in 5; gastroesophageal reflux in 3 ; cerebral palsy in 3 ; oncological disease in 2 ; neuromuscular disease in 1; AIDS in 1, andsick cell disease in 1 .

The following etiologic agents were identified using antigen detection on respiratory secretions: respiratory syncytial virus (RSV) in 85 (56.3\%), adenovirus in $3(2 \%)$, and influen$\mathrm{za}$ in $2(1.3 \%)$.

A bacterial agent was identified in respiratory secretions or blood samples in 15 children (5 bacterial co-infections): Haemophilus influenzae: 5; Streptococcus pneumoniae: 2; Streptococcus A: 2; Klebsiella pneumoniae + Staphilococcus aureus: 1; Mycoplasma pneumoniae: 1; Meningococcus: 1; Bordetella pertussis: 1; Salmonella sp: 1.

NIV was initiated due to ARF (hipoxemic/ hypercapnic) in 144 (95.4\%), apnea in 20 , exacerbation of chronic pulmonary disease in 3 , and partial obstruction of the upper airway in 5 .

\section{Non-invasive ventilation character- istics}

Continuous positive airway pressure (CPAP) was used in 72 (48\%) and BiPAP in 79 (52\%). When using CPAP, NIV was delivered through Drager Babylog 8000 plus ${ }^{\circledR}$ in 40 (26.5\%), and Infant Flow Driver ${ }^{\circledR}$ in 31 (20.5\%). When using BiPAP, Infant Flow Driver
advance/SiPAP ${ }^{\circledR}$ was used in $35(23.2 \%)$, Respironics BiPAP Vision ${ }^{\circledR}$ in 35 (23.2\%) and Respironics BiPAP Harmony ${ }^{\circledR}$ in 10 (6.6\%).

Regarding interfaces, we used a nasopharyngeal tube in 40 children, a nasal mask/nasal prongs in 99 (65.6\%), and a mouth-nose mask in $12(8 \%)$.

The nasopharyngeal tubes were mainly used with the Drager Babylog 8000 plus ${ }^{\circledR}$ when applying CPAP during our first year, due to the lack of NIV specific ventilators for infants.

The mean used pressures were $5.5-6 \mathrm{cmH}_{2} \mathrm{O}$ for EPAP/CPAP (min: 4, max: 9) and 9.5-19 cm $\mathrm{H}_{2} \mathrm{O}$ for IPAP (min: 6; max: 24) (Table 1).

\section{Sedation}

One hundred and seventeen (77.5\%) children were sedated. In 80 (53\%), chloral hydrate was used; in 35 (23\%), chloral hydrate was associated with midazolam in bolus, PRN. Four were sedated with a low dose midazolam $(1 \mu \mathrm{g} / \mathrm{Kg} / \mathrm{min})$. In thirty-four patients no pharmacological sedation was needed. These patients were mainly newborns (59\%). The percentage of patients who were not sedated was similar in both study groups (22.2 vs. $23.5 \%)$.

\section{Enteral nutrition}

Fifty-one children (33.8\%) remained fasted, $60(40 \%)$ were fed by partial enteral nutrition with a naso or orogastric tube, and in 22 , total nasogastric enteral nutrition was accomplished.

\section{Clinical progression and gasometri- cal evolution}

Baseline values of the variables did not differ between groups.

Analysis of clinical and gasometric data showed an overall significant decrease in RR, $\mathrm{HR}$ and improvement in blood gases $(\mathrm{pH}$, pC02) from hour 2, and maintained through all the study (at 4, 6, 12h), until $24 \mathrm{~h}$ after starting NIV $(\mathrm{P}<0.05)$ (Table 2).

Although these variables decreased more in the success group, the difference was not statistically significant between the two groups.

The improvement in $\mathrm{SpO}_{2} / \mathrm{FiO}_{2}$ was verified at $2,4,6,12$, and $24 \mathrm{~h}$ after initiation of NIV only in the success group $(\mathrm{P}=0,000)$; in the failure group, improvement was significant only in the first 4 hours.

\section{Non-invasive ventilation outcome}

\section{Non-invasive ventilation success}

Of the 151 episodes, 117 (77.5\%) were successfully treated with NIV and 34 children (22.5\%) needed invasive ventilation (IV).

The criteria for intubation were: apnea with bradicardia (10), frequent apnea (8), clinical deterioration (4), ARDS (3), shock with cardiac failure (1), severe hypoxemia (1), and increased hypercapnia (7).

Baseline characteristics of successful and failure groups are shown in Table 3.

\section{Predictive factors of non-invasive ventilation outcome/risk factors analysis}

To identify clinical and physiological variables associated with favorable NIV outcome, NIV success and failure groups were compared.

Univariate analysis showed that pneumonia, PIM, apnea, prematurity, bacterial coinfection, and progression to ARDS were risk factors for NIV failure $(\mathrm{P}<0.25)$ (Table 3$)$.

Using multiple logistic regression including these variables showed that the better model (higher Hosmer and Lemeshow Test, $\mathrm{P}=0.886$, and higher area under ROC) was the one including: apneia $(\mathrm{P}<0: 001$; odds ratio 15.8 ; 95\% confidence interval: $3.42-71.4$ ), bacterial co-infection $(\mathrm{P}=0.067$, odds ratio $2.68,95 \%$ confidence interval: 0.94-7.70) and pneumonia ( $\mathrm{P}<0.001$, odds ratio 31.25; 95\% confidence interval: 8.33-111.11), as independent risk factors (Table 4). In this model, PIM, prematurity, were non significant; progression for ARDS was excluded because it only occurred in three patients. When we constructed a multivariate model we concluded that the relation between factors was not an important determinant.

Patients with pneumonia who needed invasive ventilation were of younger age $(6.1 \pm 10$ months vs. $40.6 \pm 45.7$ months), the same having occurred in patients with bronchiolitis ( $0.95 \pm 0.6$ vs. $1.7 \pm 2.3$ months).

\section{Non-invasive ventilation adverse effects}

During the application of NIV we observed the following complications: nasal mucosa trauma (9), nasopharyngeal prosthesis obstruction due to mucus hypersecretion (10), desynchronization (5), pressure ulcers (4), inadequate humidification (1), gastric disten-

Table 1. Non-invasive ventilation parameters $(\mathrm{n}=151)$.

\begin{tabular}{lllcccccc} 
& Oh & 1 h & $2 \mathrm{~h}$ & $\mathbf{4 h}$ & $6 \mathrm{~h}$ & $\mathbf{1 2 h}$ & $24 \mathrm{~h}$ & $48 \mathrm{~h}$ \\
EPAP & $5.5 \pm 1$ & $5.6 \pm 1$ & $5.7 \pm 1$ & $5.8 \pm 1$ & $6 \pm 1$ & $6 \pm 1$ & $6 \pm 1.1$ & $6 \pm 1$ \\
IPAP & $9.5 \pm 2.7$ & $9.8 \pm 3$ & $9.8 \pm 3$ & $10 \pm 3$ & $10 \pm 2.5$ & $9.8 \pm 2.6$ & $10 \pm 2.5$ & $9.5 \pm 2.6$ \\
\hline FiO2 & $40 \pm 1.5$ & $40 \pm 1.3$ & $38.5 \pm 1.2$ & $37.7 \pm 1.1$ & $36.3 \pm 1$ & $36 \pm 1.3$ & $33.4 \pm 1$ & $33.6 \pm 7.6$ \\
\hline
\end{tabular}

There were no differences between both groups. EPAP, Expiratory positive airway pressure; IPAP Inspiratory positive airway pressure; $\mathrm{FiO}_{2}$, Fraction of inspired oxygen 
Table 2. Evolution of clinical and gasometric parameters. Clinical evolution for the first 24h: paired T test showed significant improvement at 2. 4. 6. 12. and $24 \mathrm{~h}$ for all parameters in group $\mathrm{A}$ as well as in group $\mathrm{B}$ for respiratory and cardiac rate.

\begin{tabular}{|c|c|c|c|c|c|c|c|}
\hline & Group & Pre-NIV & $2 h(n=142)$ & 4h $(n=137)$ & $6 h(n=132)$ & $12 \mathrm{~h}(\mathrm{n}=122)$ & $24 h(n=102)$ \\
\hline \multirow[t]{2}{*}{ Respiratory rate (cpm) } & A & $59 \pm 15.4$ & $43.4 \pm 13.2(\mathrm{P}<0.001)$ & $40.5 \pm 11.3(\mathrm{P}<0.001)$ & $41.2 \pm 13(\mathrm{P}<0.001)$ & $39 \pm 10.4(\mathrm{P}<0.001)$ & $37.3 \pm 10.2(\mathrm{P}<0.001)$ \\
\hline & B & $59.4 \pm 18.7$ & $42.4 \pm 9.1(\mathrm{P}=0.001)$ & $43.6 \pm 12(\mathrm{P}=0.005)$ & $42 \pm 10.6(\mathrm{P}=0.004)$ & $40.3 \pm 13.2(\mathrm{P}<0.001)$ & $38.5 \pm 13(\mathrm{P}=0.01)$ \\
\hline te (bpm) & $\begin{array}{l}\text { A } \\
\text { B }\end{array}$ & $\begin{array}{c}164.5 \pm 19 \\
164.7 \pm 17.6\end{array}$ & $\begin{array}{c}149 \pm 19.3(\mathrm{P}<0.001) \\
151 \pm 19(\mathrm{P}=0.01)\end{array}$ & $\begin{array}{l}147 \pm 14.5(\mathrm{P}<0.001) \\
149 \pm 19.4(\mathrm{P}=0.001)\end{array}$ & $\begin{array}{c}143 \pm 18(\mathrm{P}<0.001) \\
145 \pm 18.6(\mathrm{P}<0.001)\end{array}$ & $\begin{array}{c}140 \pm 15.1(P<0.001) \\
143 \pm 18(P<0.001)\end{array}$ & $\begin{array}{l}138 \pm 14.5(\mathrm{P}<0.001) \\
141.6 \pm 13(\mathrm{P}=0.001)\end{array}$ \\
\hline \multirow[t]{2}{*}{$\mathrm{pH}$} & A & $7.29 \pm 0.07$ & $\begin{array}{c}7.35 \pm 0.06(\mathrm{P}<0.001) \\
(\mathrm{n}=63 / 117)\end{array}$ & $\begin{array}{c}7.35 \pm 0.05(\mathrm{P}<0.001) \\
(\mathrm{n}=66 / 117)\end{array}$ & $\begin{array}{c}7.35 \pm 0.05(\mathrm{P}<0.001) \\
(\mathrm{n}=54 / 114)\end{array}$ & $\begin{array}{c}7.37 \pm 0.05(\mathrm{P}<0.001) \\
(\mathrm{n}=74 / 106)\end{array}$ & $\begin{array}{c}7.39 \pm 0.05(\mathrm{P}<0.001) \\
(\mathrm{n}=75 / 92)\end{array}$ \\
\hline & B & $7.27 \pm 0.09$ & $\begin{array}{c}7.31 \pm 0.05(\mathrm{P}=0.006) \\
(\mathrm{n}=16 / 25)\end{array}$ & $\begin{array}{c}7.33 \pm 0.06(P=0.07) \\
(n=15 / 20)\end{array}$ & $\begin{array}{c}7.34 \pm 0.06(P=0.03) \\
(n=12 / 18)\end{array}$ & $\begin{array}{c}7.33 \pm 0.05(\mathrm{P}=0.07) \\
(\mathrm{n}=11 / 16)\end{array}$ & $\begin{array}{c}7.35 \pm 0.03(P=0.01) \\
(n=7 / 10)\end{array}$ \\
\hline $\begin{array}{l}\text { Carbon dioxide partial } \\
\text { pressure }\end{array}$ & A & $\begin{array}{l}62.5 \pm 12.5 \\
63 \pm 10.7\end{array}$ & $\begin{array}{c}58.2 \pm 11.7(\mathrm{P}<0.001) \\
(\mathrm{n}=63 / 117) \\
60.4 \pm 9.5(\mathrm{P}=0.03) \\
(\mathrm{n}=16 / 25)\end{array}$ & $\begin{array}{c}54.1 \pm 7.1(\mathrm{P}<0.001) \\
(\mathrm{n}=66 / 117) \\
56.7 \pm 13.4(\mathrm{P}=0.048) \\
(\mathrm{n}=15 / 20)\end{array}$ & $\begin{array}{c}56 \pm 9.6(\mathrm{P}<0.001) \\
(\mathrm{n}=54 / 114) \\
57 \pm 14(\mathrm{P}=0.01) \\
(\mathrm{n}=12 / 18)\end{array}$ & $\begin{array}{c}52.5 \pm 6(\mathrm{P}<0.001) \\
(\mathrm{n}=74 / 106) \\
57 \pm 12(\mathrm{P}=\mathrm{ns}) \\
(\mathrm{n}=11 / 16)\end{array}$ & $\begin{array}{c}51.5 \pm 6.3(\mathrm{P}<0.001) \\
(\mathrm{n}=75 / 92) \\
57.7 \pm 9(\mathrm{P}=\mathrm{ns}) \\
(\mathrm{n}=7 / 10)\end{array}$ \\
\hline $\mathrm{SpO}_{2} / \mathrm{FiO}_{2}$ & A & $2.6 \pm 0.7$ & $\begin{array}{c}2.74 \pm 0.6(\mathrm{P}<0.001) \\
(\mathrm{n}=101) \\
2.5 \pm 0.8(\mathrm{P}<0.001) \\
(\mathrm{n}=24)\end{array}$ & $\begin{array}{c}2.8 \pm 0.6(\mathrm{p}<0.001) \\
(\mathrm{n}=97) \\
2.6 \pm 0.66(\mathrm{P}=0.003) \\
(\mathrm{n}=20)\end{array}$ & $\begin{array}{c}2.9 \pm 0.65(\mathrm{P}<0.001) \\
(\mathrm{n}=96) \\
2.7 \pm 0.75(\mathrm{P}=\mathrm{ns}) \\
(\mathrm{n}=18)\end{array}$ & $\begin{array}{c}3.0 \pm 0.65(\mathrm{P}<0.001) \\
(\mathrm{n}=87) \\
2.7 \pm 0.74(\mathrm{P}=0.016) \\
(\mathrm{n}=16)\end{array}$ & $\begin{array}{c}3.0 \pm 0.57(\mathrm{P}<0.001) \\
(\mathrm{n}=71) \\
2.67 \pm 1.0(\mathrm{P}=\mathrm{ns}) \\
(\mathrm{n}=10)\end{array}$ \\
\hline
\end{tabular}

Group A: Non-invasive ventilation (NIV) success group ( $\mathrm{n}=117$ ); Group B: NIV failure group ( $\mathrm{n}=34)$. At 2.4.6.12 and 24h number of patients on NIV is indicated. P value: two-tailed T-test - analysis of variance of values before and after NIV (at 2. 4.612 and 24h) in each group. Number of patients who had gasimetric evaluation at the considered hours is referred. Pulse oximetric saturation/fraction of inspired oxygen (SpO2/FiO2) is not considered when $\mathrm{SpO}_{2}$ is $>96 \%$.

Table 3. Comparison of group A (success) and B (failure) - clinical characteristics - univariate analysis.

\begin{tabular}{|c|c|c|c|c|}
\hline & $\begin{array}{l}\text { Total sample } \\
\qquad(\mathrm{n}=151)\end{array}$ & $\begin{array}{l}\text { NIV success group } \\
\qquad(n=117)\end{array}$ & $\begin{array}{l}\text { NIV failure group } \\
(\mathrm{N}=34)\end{array}$ & P value \\
\hline \multicolumn{5}{|l|}{ Age } \\
\hline $\begin{array}{l}<1 \text { month } \\
<2 \text { months }\end{array}$ & $\begin{array}{c}79 \\
109\end{array}$ & $\begin{array}{l}61 \\
84\end{array}$ & $\begin{array}{l}18 \\
25\end{array}$ & $\begin{array}{l}0.5 \\
\text { ns }\end{array}$ \\
\hline $\begin{array}{l}\text { Age (mean } \pm \text { sd) } \\
\text { Sex (F:M) } \\
\text { Weight (mean } \pm \text { sd) }\end{array}$ & $\begin{array}{c}7.2 \pm 20.3 \\
74: 77 \\
5.1 \pm 4.9\end{array}$ & $\begin{array}{l}7.9 \pm 22.6 \\
55: 62 \\
5.3 \pm 5.4\end{array}$ & $\begin{array}{l}4.9 \pm 9 \\
19: 15 \\
4.4 \pm 3\end{array}$ & $\begin{array}{l}\text { ns } \\
\text { ns } \\
\text { ns }\end{array}$ \\
\hline PIM* & & $3.4 \pm 7.0(n=80)$ & $6.9 \pm 9.0(\mathrm{n}=23)$ & 0.049 \\
\hline $\begin{array}{l}\text { Diagnosis (\%) } \\
\text { Bronquiolitis } \\
\text { Pneumonia } \\
\text { Apnea } \\
\text { Bacterial co-infection } \\
\text { Septic shock } \\
\text { Acute respiratory distress syndrome }\end{array}$ & $\begin{array}{c}102(67.5) \\
44(29.1) \\
20(13.2 \%) \\
43(28.5 \%) \\
3 \\
3 \\
\end{array}$ & $\begin{array}{c}95 \\
18 \\
9 \\
26 \\
2 \\
0\end{array}$ & $\begin{array}{c}7 \\
26 \\
11 \\
17 \\
1 \\
3\end{array}$ & $\begin{array}{c}0.00 \\
0.00 \\
0.001 \\
0.001 \\
\text { n.s. } \\
0.011\end{array}$ \\
\hline $\begin{array}{l}\text { Past history } \\
\text { Prematurity } \\
\text { Chronic pulmonary disease } \\
\text { Neurodevelopment delay }\end{array}$ & $\begin{array}{c}27(18 \%) \\
10(6.6 \%) \\
12\end{array}$ & $\begin{array}{c}17 \\
10 \\
8\end{array}$ & $\begin{array}{c}10 \\
0 \\
4\end{array}$ & $\begin{array}{c}0.045 \\
0.07 \\
0.27\end{array}$ \\
\hline Duration of NIV (hours) & $48.3 \pm 39$ & $56.4 \pm 38$ & $20.3 \pm 28$ & 0.00 \\
\hline Duration of hospital stay (days) & $9.7 \pm 9.5$ & $8.4 \pm 8.8$ & $14.5 \pm 10.2$ & 0.003 \\
\hline
\end{tabular}

*PIM only determined in children > 1 month and < 16 years.NIV, non-invasive ventilation; PIM, pediatric index of mortality score; ns, not significant.

Table 4. Multivariate analysis regression for risk factors.

\begin{tabular}{lccc} 
& Odds ratio & $95 \%$ confidence interval for odds ratio \\
Apnea & 15.8 & $3.42-71.4$ & P value \\
Bacterial co-infection & 2.68 & $0.94-7.70$ & 0.067 \\
\hline Pneumonia & 31.25 & $8.33-111.11$ & 0.000 \\
\hline
\end{tabular}




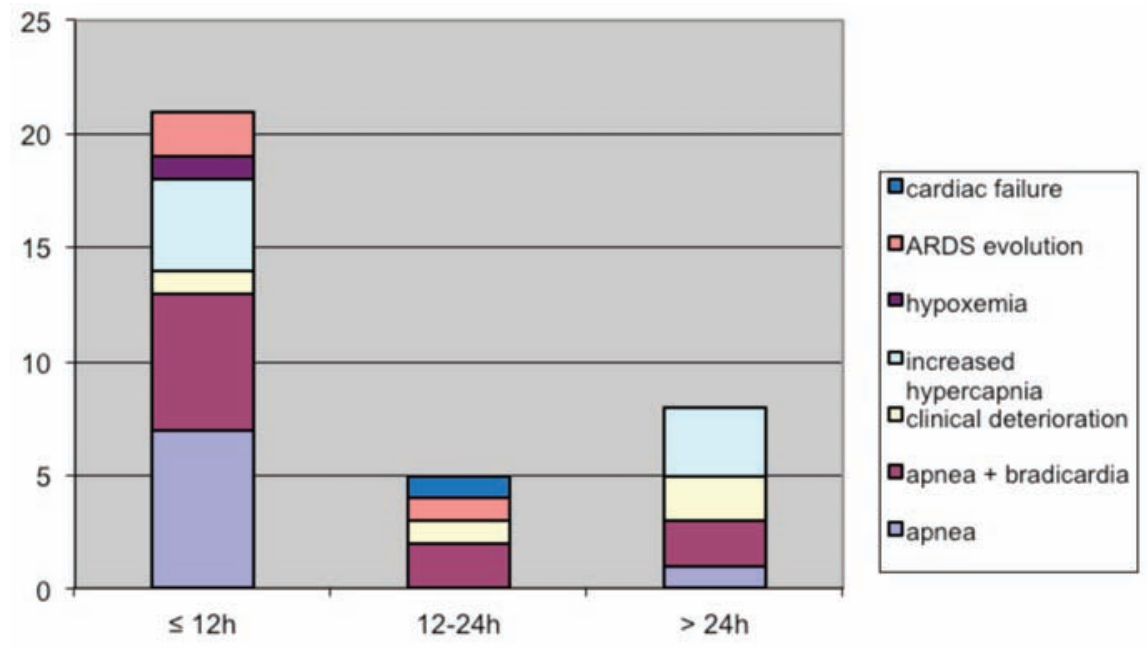

Figure 1. Timing and reasons for endotracheal intubation. $(n=34)$. Non-invasive ventilation failure $\leq 12 \mathrm{~h}=21 ; 12-24 \mathrm{~h}=5 ;>24 \mathrm{~h}=8$; ARDS, Acute respiratory distress syndrome.

sion (1), and conjunctivitis (1). None of these complications were responsible for NIV failure.

\section{Non-invasive ventilation duration}

The mean duration of NIV was $48.3 \pm 39$ hours (range 1-209 hrs). NIV duration in the failure group was: <1h: in 4 patients; between 1 and 12h: in 17; and $>12 \mathrm{~h}$ : in 13 . Timing and reasons for endotracheal intubation are shown in Figure 1.

\section{Hospital stay}

The mean hospital stay was $9.7 \pm 9.5$ days (median 8). The difference between the two groups was statistically significant (Table 3 ).

\section{Mortality}

Two patients died; both deaths were related with underlying disease (AIDS and end-stage oropharynx carcinoma).

\section{Discussion}

Our results show that pediatric patients with acute respiratory insufficiency/distress can improve with NIV used as a primary ventilatory support. The overall success rate was $77.5 \%$. Clinical evidence of response was associated with improvement in RR and $\mathrm{HR}$ as well as blood gases ( $\mathrm{pH}$ and $\left.\mathrm{pCO}_{2}\right)$. This improvement was evident, and statistically significant, since the first hours of NIV, and was observed in both the success and failure group for RR and $\mathrm{HR}$. Decrease of $\mathrm{pCO}_{2}$ was not significant in the failure group at 12 and $24 \mathrm{~h}$, but gasimetric data is available in a small number of patients.

The indirect measure of oxygenation using the $\mathrm{SatO}_{2} / \mathrm{FiO}_{2}$ ratio also showed a significant improvement in the success group, but was not very consistent in the failure group.

This clinical improvement has been described in previous studies. ${ }^{9-15}$

NIV as primary ventilatory support prevents the clinical deterioration of some patients, where it could lead to the need for intubation, and ensures a better respiratory comfort, shown by the improvement in clinical parameters. Previous studies have shown success rates for NIV in the pediatric population to be between 57 and $92 \% .8-18$ In the retrospective study done by Javouhey et al., ${ }^{20}$ a ventilatory strategy using NIV as primary ventilatory support in severe bronchiolitis was associated with a decreased incidence of ventilator associated pneumonia, less oxygen support, and a reduction in hospital stay, when compared with a period when NIV was not used. The success rate was of $81 \%$.

Different success rates are probably related to heterogeneity of the groups regarding age and diagnosis.

In this study, independent risk factors for NIV failure were apnea and pneumonia. These factors were also identified in previous studies. ${ }^{9-15}$ Other factors were also previously, considered relevant: younger age, 11 higher PRISM score, ${ }^{10-14}$ ARDS $^{9}$ type I ARF,10 and failure to decrease RR.9-10 In our study the patients were in majority small infants, the severity score used was PIM, pneumonia is associated with type I ARF; the clinical and gasometric improvement in our group didn't seem to be good predictive factors.

In a 5-year observational study, where 114 children with different causes of respiratory failure (community-acquired pneumonia, immunodeficiency, and sickle cell disease) were included, Essouri et al.,$^{9}$ illustrated an overall success rate of $77 \%$. Favorable outcome was predicted by breathing pattern evolution within the first 2 hrs of NIV (a significant decrease in $\mathrm{pCO}_{2}$ and $\mathrm{RR}$ was observed in the NIV success group). Multivariate analysis showed that ARDS and a high PELOD score were independent risk factors for NIV failure. ${ }^{9}$

The largest prospective study of NIV outcome predictors in pediatric ARF, included 116 episodes of NIV.10 This study included a typical heterogeneous, critically ill pediatric population with a median age of 10.3 months (0.6$169.7)$. The success rate was $84 \%$. Three independent risk factors for NIV failure were identified: type 1 ARF, high PRISM score, and lower RR decrease during initial NIV phase.

Hypoxemic ARF patients are more likely to suffer NIV failure, as shown by most of the previous studies in adults and children.6,9,10 In adult patients with hypoxemic respiratory failure, pneumonia, ARDS, or failure of $\mathrm{PaO}_{2} / \mathrm{FiO}_{2}$ increase $>146$ after the first hour of NIV therapy have been associated with increased risk of NIV failure..$^{2,5,6}$

In our series NIV failure occurred in 26 out of 44 patients with pneumonia, and in only 7 out of 95 patients with bronchiolitis. Pneumonia and progression to ARDS were risk factors for NIV failure.

The fact that the $\mathrm{SpO}_{2} / \mathrm{FiO}_{2}$ improvement was not consistent in the failure group is probably associated with type 1 ARF predominance in this group. For this reason, it is extremely important to classify patients as type 1 or 2 ARF before starting NIV.10

PRISM score has already been illustrated as a predictive factor for NIV outcome. ${ }^{10-13}$ In our study PIM was higher in the failure group, although not significant in the multiple logistic regression.

Younger age, shown to be a risk factor for NIV failure in several other studies, ${ }^{10,11,13}$ may be related to other associated factors (e.g. increased occurrence of apnea in the neonatal period) or technical problems (e.g. use of inappropriate interfaces, use of NIV ventilators without a specific trigger for this age group).

Our study had a very low median age [1 month: (0.26-156)], with the main diagnosis having been bronchiolitis ( $n=102 ; 67.5 \%)$ Other studies that have included only infants with bronchiolitis also had a low median age. ${ }^{12,13}$

The use of NIV in severe bronchiolitis, and its physiological effects in the improvement of respiratory work (clinically evaluated by a reduction in the RR) and blood gas exchange, have been described since 1981.12-14,19,21

Soong et al.,21 studied 10 infants with bronchiolitis and impending respiratory failure in a non-randomized study. They reported improvement in clinical signs and symptoms, and 
physiologic parameters (HR, RR, $\mathrm{PaCO}_{2}$, and oxygenation index) after two hours of CPAP.

S. Larrar et al.,12 illustrated significant improvement in respiratory status shown by decrease in RR and HR, in a prospective study with 53 infants with bronchiolitis. The success rate was $75.5 \%$. Predictive factors associated with NIV failure were a higher PRISM score and a smaller initial reduction in the $\mathrm{PaCO}_{2}$ (between the $12^{\text {th }}$ and $16^{\text {th }}$ hour). This $\mathrm{PaCO}_{2}$ decrease was significantly higher in the success group $(\mathrm{P}=0.003)$. In the failure group, PRISM score was significantly higher when compared to the success group $(9.2 \pm 4.1 \mathrm{vs}$. $5.1 \pm 3.2, \mathrm{P}=0.002) .12$

In a series of 69 infants with bronchiolitis, Campion et al.,13 had a NIV success rate of $83 \%$. They presented a significant decrease in $\mathrm{pCO}$, and an increase in $\mathrm{pH}$ at 2 and 4 hours after beginning NIV. Factors associated with NIV failure were $\mathrm{pCO}_{2}$ at admission ( $\left.80 \mathrm{vs} .66\right)$, higher PRISM score (15 vs. 10), and apnea.

In an analysis of 47 patients with bronchiolitis treated with NIV, Mayordomo-Colunga et al. ${ }^{11}$, identified apnea $(23.1 \%$ vs. $75 \%$; $\mathrm{P}=0.004)$, background medical history $(84.6 \%$ vs. $50 \% ; \mathrm{P}=0.029$ ) and smaller reduction in the HR at 1 and 12 hours after beginning NIV, as risk factors for NIV failure. A reduction in the HR by 11 bpm or higher predicted NIV success with $64.1 \%$ sensibility and $87.5 \%$ specificity. They also observed that patients in the failure group presented a lower RR before initiating $\mathrm{NIV}$, and a smaller reduction in this parameter in the following hours. Other parameters with statistical relevance between the two groups were weight and age.

Thia et al.,14 conducted a randomized controlled trial $(\mathrm{n}=31)$ comparing nasal CPAP and standard treatment in children with bronchiolitis. There was a significantly greater change in $\mathrm{pCO}_{2}$ following CPAP given as first line therapy when compared to CPAP given as second option. No significant differences were seen in HR or RR. The difference seen between early and late use of NIV is probably related to the fact that early treatment prevents the development of additional airway collapse and further tiring. Therefore, it appears that early use of NIV slows and reverses the natural progression of the disease, supporting its early use in clinical practice. ${ }^{14}$

Another prospective study, conducted by Bernet et al., 15 included 42 children with a median age 2.45 years (range, 0.01-18 yrs). The success rate was $57 \%$ having been composed by a very heterogeneous group of patients (bronchiolitis, pneumonia, postoperative congenital cardiopathy, hyaline membrane disease, etc). There was a significant improvement of respiratory variables $\left(\mathrm{pH}, \mathrm{pCO}_{2}, \mathrm{RR}\right.$ and HR) during the first 8 hours in both groups. During the first hour, a decrease in RR was documented only in the success group. FiO2 after 1 hour of NIV was significantly lower in responders when compared to nonresponders $(\mathrm{P}<0.02)$. An $\mathrm{FiO}_{2}>0.8$ at 1 hour of NIV predicted failure with a sensitivity of $56 \%$, specificity $83 \%$, positive predictive value of $71 \%$, and negative predictive value of $71 \%$. $\mathrm{FiO}_{2}$ at 1hour was not different between patients with and without successful NIV> 24hrs $(\mathrm{P}=0.58)$.

Other studies have identified the occurrence of apnea as a predictive factor of NIV failure. $11,13,19$

Predictors of NIV success or failure are helpful in selecting patients. Most studies show that the best predictor of NIV success is a favorable response to NIV within the first hours (reduction in $\mathrm{RR}$, improvement in $\mathrm{pH}$, improvement in oxygenation, reduction in $\mathrm{PaCO}_{2} \cdot{ }^{10-19}$ This emphasizes the importance of the close monitoring in these patients. If a reduction in RR or HR fails to occur, close surveillance must be undertaken and ETI should be considered.

Complications were minimal, therefore not interfering with the application or efficacy of NIV. There were no documented cases of barotrauma or aspiration. The occurrence of gastric distension was non-significant (1 case only), and this was probably related to the use of a nasogastric tube for enteral feeding. Although agitation during initial mask placement was observed in several infants, no patient required NIV discontinuation due to poor tolerance. Skin lesions occurred more frequently during the early phase of NIV use in our Unit. Incidence decreased with the routine use of protective patches over pressure points, prior to mask application. The potential incapacity of young children to trigger the inspiratory pressure support is one of the limitations of NIV use in small children. A second technical challenge pertains to the correct mask interface selection. Important issues to consider when selecting an interface are patient comfort and optimum fit to minimize leakage. In some patients, the use of sedation is an important adjuvant to the success of NIV, and may help overcome synchronization problems. This study shows the relevance of the use of NIV guidelines leading to a greater utilization of NIV and, by taking risk factors for NIV failure into account, to better clinical judgment. Once begun, patients should be closely monitored; attention should be paid to vital signs, gas exchange, comfort, and tolerance.

The use of NIV in children does not mean that less monitoring and/or care is needed, when compared to invasive forms of mechanical ventilation. In fact, after initiation of NIV for acute respiratory distress, close bedside assessment of efficacy is essential. Children treated with NIV must be observed by qualified professionals, guided by the use of cardio-res- piratory monitoring, pulse oximetry, and blood gases when necessary. Limitations of our study are related to the lack of randomization, lack of standardized weaning protocols for infants treated with NIV, and probably to the use of subjective criteria for initiating invasive ventilation in some patients. Although randomized controlled studies regarding the use of NIV in children are needed, 25 this may post an ethical problem since scientific evidence defending the use of NIV already exists. Published retrospective and prospective studies show that NIV is in fact an effective alternative ventilatory support method that should be applied early in the course of respiratory distress, in order to avoid clinical deterioration and prevent ETI in some patients.

Factors essential to NIV success include the careful selection of patients, a properly timed intervention, a comfortable and well-fitting interface, coaching and encouragement of patients, careful monitoring, and a skilled and motivated team. ${ }^{6}$ Indeed, the efficacy of NIV also seems to be closely linked to the experience and motivation of the care team. ${ }^{9}$

Patients that may benefit from the use of NIV are being more clearly defined. When taking into account the fact that early initiation of NIV seems to be the major factor affecting NIV success, defining specific criteria for NIV implementation is difficult.

The elaboration of prospective, multi-centered studies is still necessary, in order to continue identifying possible predictors of NIV success or failure.

\section{Conclusions}

When instituted at an early phase of ARF, NIV can be effective in improving or reversing acute respiratory distress in selected patients, and can decrease the need for endotracheal intubation. The increased use of NIV in our PICU during the past years clearly reflects the interest, motivation and experience of the entire PICU staff.

This study brings additional data to literature on NIV used on acute respiratory setting in children, focusing on the efficacy of NIV, and trying to identify possible predictors of failure or success.

As suggested by some other authors ${ }^{9}$ we propose this ventilatory support as a first line treatment in children with acute respiratory distress. However children with hypoxemic ARF should start NIV with special attention, as evolution to ARDS is highly associated with failure in this group.

It is possible that with increasing experience, guidelines for NIV pediatric use may be appropriately refined improving NIV outcome in children. With technical advances and new 
evidence of its proper application, this technique is likely to expand.

\section{References}

1. Teague WG. Non-invasive positive pressure ventilation: current status in paediatric patients. Pediatr Resp Rev 2005;6:5260 .

2. Garpestad E, Brennan J, Hill NS. Noninvasive ventilation for critical Care. Chest 2007;132:711-20.

3. Rimmemsberger PC. Noninvasive pressure support ventilation for acute respiratory failure in children. Schweiz Med Wochenschr 2000;130:1880-6.

4. Teague WG. Non-invasive ventilation in the Pediatric Intensive Care Unit for children with acute respiratory failure. Pediatric Pulmonol 2003;35:418-26.

5. Antonelli M, Conti G, Esquinas A, et al. A multi-center survey on the use in the clinical practice of NIV as first intervention for acute respiratory distress syndrome. Crit Care Med 2007;35:18-25.

6. Antonelli M, Conti G, Moro Ml, et al. Predictors of failure of noninvasive positive pressure ventilation in patients with acute hypoxemic respiratory failure: a multi-center study. Intensive Care Med 2001;27:1718-28.

7. Ramanathan R, Sardesai S. Lung protective ventilatory strategies in very low birth weight infants. J Perinatol 2008;28:S41-6.

8. Soto R, Maquilon C, Saldias F. Ventilación no invasive en pacientes con daño pulmonar agudo. Rev Chil Enf Respir 2008;24:215-8.

9. Essouri S, Chevret L, Durand P, et al.
Noninvasive positive pressure ventilation: five years experience in a pediatric intensive care unit. Pediatr Crit Care Med 2006;7:329-34.

10. Mayordomo-Colunga J, Medina A, Rey C, et al. Predictive factors of non invasive ventilation failure in critically ill children: a prospective epidemiological study. Intensive Care Med 2009;35:527-36.

11. Mayordomo-Colunga J, Medina A, Rey C, et al. Predictores de éxito y de fracas en la ventilación no invasive en la bronchiolitis aguda. An Pediatr (Barc) 2009;70:34-9.

12. Larrar S, Essouri S, Durand P, et al. [Effects of nasal continuous positive airway pressure ventilation in infants with severe acute bronchiolitis]. Arch Pediatr. 2006;13:1397-03. [Article in French]

13. Campion A, Huvenne $H$, Leteurtre $S$, et al. [Non-invasive ventilation in infants with severe infection presumably due to respiratory syncytial virus: feasibility and failure criteria]. Arch Pediatr 2006;13:1404-9. [Article in French]

14. Thia LP, McKenzie SA, Blyth TP, et al. Randomised controlled trial of nasal continuous positive airway pressure (CPAP) in bronchiolitis. Arch Dis Child 2008;93:45-7.

15. Bernet V, Hug MI, Frey B. Predictive factors for the success of noninvasive mask ventilation in infants and children with acute respiratory failure. Pediatr Crit Care Med 2005; 6:660-4.

16. Thill PJ, McGuire JK, Baden HP, et al. Noninvasive positive pressure ventilation in children with lower airway obstruction. Pediatr Crit Care Med 2004;5:337-42.

17. Fortenberry JD, Toro J, Jefferson LS, et al. Management of pediatric acute hypoxemic respiratory insufficiency with bilevel posi- tive pressure (BIPAP) nasal mask ventilation. Chest 1995;108:1059-64.

18. Padman R, Lawless ST, Kettrick RG. Noninvasive ventilation via bilevel positive airway pressure support in pediatric practice. Crit Care Med 1998; 26:169-73.

19. Beasley J, Jones SF. Continuous positive airway pressure in bronchiolitis. BMJ 1981;283:1506-8.

20. Javouhey E, Barats A, Richard N, et al. Non-invasive ventilation as primary support for infants with severe bronchiolitis. Intensive Care Med 2008;34:1608-14.

21. Soong WJ, Hwang B, Tang RB. Continuous positive airway pressure by nasal prongs in bronchiolitis. Pediatr Pneumonol 1993; 16:163-6.

22. Medina Villanueva A, Prieto Espuñes S, Los Arcos Solas M, et al. Aplicación de ventilación no invasive en una unidad de cuidados intensivos pediátricos. An Pediatr (Barc) 2005;62:13-9.

23. Medina A, Pons M, Martino-Torres F. Ventilación no invasiva en pediatria. 1st Ed. 2004. Sociedad Española de Cuidados Intensivos Pediátricos. Available from: http://secip.blogspot.com/search/label/Libr os\%20de\%20Interés

24. Khemani RG, Patel NR, Bart RD, Newth CJ. Comparison of the pulse oximetric saturation/Fraction of Inspired oxygen ratio and the PaO2/fraction of Inspired Oxygen Ratio in children. Chest 2009;135:662-8.

25. Shah PS, Ohlsson A, Shah JP. Continuous negative extrathoracic pressure or continuous positive airway pressure for acute hypoxemic respiratory failure in children (review). Cochrane Database Syst Rev 2009;1-16. 